\title{
Interpretação e Poder
}

\author{
Luís Cos'ta Lima
}

A crítica literária tem no século $\mathrm{XX}$ uma importância que antes desconhecera. Até então, fora considerada um ornato, necessária apenas enquanto adorno, que tinha a função de ressaltar o desenho da arte. Ajustava-se ao papel de mediadora entre a obra e o leitor, espécie de correia de transmissão entre a fonte e o usuário. Seu papel era comparável ao que hoje concedemos à música no cinema, que deve existir para se disfarçar, estar presente para ressaltar a presença do que não é ela: a trama desenvolvida pelos personagens.

Com a crítica contemporânea, perde-se a cadeia visível que unia o leitor, o crítico e a obra. Pouco posterior, enquanto movimento, ao surgir da poesia moderna com Baudelaire, sua diferença quanto à crítica do passado tem a ver com as mesmas razões sociológicas que $\mathrm{W}$. Benjamin apontara como determinantes do caráter de Fleurs du mal: a perda de uma Erlebnis comunitária, a que sucedera a experiência de choque, correlatas ao aparecimento das grandes metrópoles, na etapa de institucionalização do capitalismo. Daí resultava, quer o obstáculo ao êxito comunicativo da poesia lírica (1), quer a dificuldade em a prosa manter a figura do Narrador, como mais adiante testemunharia a obra proustiana (2), pois tanto o lirismo quanto o Narrador supõem uma comu- nidade de sentimentos, de valores e de crenças que tornam $o$ ato da leitura semelhante a uma câmara de ecos, que desdobrasse o som sem nunca tornar ininteligível o claro timbre da voz originária, individual em sua recepção, coletiva em sua matéria prima. A literatura moderna é contemporânea da anomia, do sentimento de desagregação, durkheimiana. Mas que significará uma crítica que nasce da constante experiência de choque, do anonimato e da desagregação, senão uma atividade que, já não contando com o endosso prévio dos leitores que reconheceriam a natureza (poética, literária) dos objetos de que ela tratava, necessita se indagar o que torna poético um recurso, o que transforma as frases em literárias, Enquanto o poético correspondeu à expectativa do que se tinha por tal, a crítica podia ornar com suas letras um desenho de cuja natureza não se duvidava. Embora a história da crítica antes mostre o atraso em que seus personagens geralmente permaneceram (3), pode-se dizer que, a partir da segunda metade do século XIX, a análise da literatura foi forçada a olhar mais intensamente para

(*) Introdução de $A$ Perversão analítica (sobre a obra Cornélio Penna), a ser proximamente lançado pela Editora Imago. 
si mesma, com a pergunta de se ainda (ou já) seria capaz de cumprir o que se propõe. A necessidade de auto-análise só não se impõe quando, de tal maneira confiamos em nossa própria capacidade, que damos por certa a qualidade de nosso corpo. Seria estranha que esta fosse a situação da crítica contemporânea, seja por sua relativa novidade, seja pela época em que apareceu. Como diz Benedito Nunes, o tempo em que a crítica contemporânea nasceu é um "tempo infeliz". Isso não significa que seja mais decepcionante que outros, mas apenas exigir de nós o que se impõe apenas no momento da infelicidade: a desconfiança que nos conduz ao auto-exame. Pressupondo então esta necessidade, colocamos a pergunta: que dá ao crítico o direito de falar sobre o texto, de maneira menos vaga, que assegura a alguém a legitimidade de sua interpretação,

Dentro de uma órbita estritamente jurídica, diremos que tal direito é confiado a alguém que tem o poder de executá-lo. A questão do direito então se desloca para a do poder. Dentro da mudança, acrescentemos ser este poder determinado por um conjunto de normas historicamente mutáveis, vigentes no interior do sistema literário. Uma colocação esquemática nos permite localizar três camadas históricas diversas:

1 .

A que se estende da Ars poetica horaciana até ao fim da primeira metade do século XVIII. O poder era então forjado pelo conhecimento das regras das preceptísticas. O direito da interpretação cabia ao gramático e ao preceptista, qualificações normalmente preenchidas pela mesma pessoa. Este período, preparado pela chamada crítica helenística, desenvolve um dos ramos que deriva da reflexão grega clássica sobre a arte.
2

A segunda camada desenvolve, ao invés, o ramo propriamente interpretativo que florescera com Platão e Aristóteles. Contemporânea à "crise da autoridade" que, no sistema literário abala o prestígio das preceptísticas, o poder passa então a ser estabelecido pela explicação estética, que vem ocupar o vazio deixado pelo descrédito das normas impositivas (4). Mais tarde, com o impacto do romantismo, àquela força geradora se acrescenta uma segunda: a força do esclarecimento autoral. Combinados, estes geradores do novo poder se diferenciam porquanto suas normas fundadoras pretendem ser explicativas e não mais impositivas, conforme se dava na camada anterior. Hoje, contudo, quando se começa a sistematizar a crítica da estética (cf. L.C.L. : 1973, cap. 1), reconhecemos que, em virtude da explicação estética não conseguir se desvencilhar do espelhismo conteudista (5), ela tendia também a se estabelecer como um princípio impositivo.

O mesmo se dava quanto à segunda força geradora do direito de interpretação. Por força do individualismo e do prestígio daí concedido à intenção autoral, a palavra do criador passava a desempenhar um papel igualmente impositivo. Em 1864, numa passagem cujo brilho hoje mais se destaca, Flauber escrevia: "Onde se conhece uma crítica que se inquiete com a obra em si, de uma maneira intensa? Analisa-se com muita sutileza o meio em que ela se produziu e as causas que a provocaram: mas a poética insciente? de onde resulta? sua composição, seu estilo? o ponto de vista do autor? Jamais!" (in Wellek: 1956, 478). O trecho de Flaubert mostra, ao lado de sua terrível antecipação - a pergunta pela "poétique inciente" —, que o prestígio de "le point du vue de l'auteur" não era empregado 
tanto como explicação da obra, mas sim como imposição de seu significado.

3.

A terceira camada supõe o êxito do combate contra o culto romântico da voz do autor - culto, na verdade, de influência muito mais prolongada do que o determinismo tainiano a que implicitamente se referia Flaubert - , empreendido em nome do melhor conhecimento da obra. Trata-se então de propor, como faria Eliot em 1919, uma "teoria impessoal da poesia", que considerasse o poema, não como a expressão de uma personalidade ou como a busca de fixar novos matizes emocionais, mas sim como um trabalho específico, que transforma um meio comum, a linguagem, em um veículo diferenciado.

A proposta de Eliot - hoje um lugar comum para qualquer iniciante no estudo da literatura - partia da mesma pretensão que há cinquenta anos orientara a demanda de Flaubert: tornar a crítica uma atividade competente, menos interessada em persuadir o leitor das qualidades de seu comentário do que em ser um modo de conhecimento. Postular esta exigência, de aparência banal, contudo impôs a Eliot opor-se ao culto da personalidade do artista, comparando o trabalho deste ao realizado pela catálise, na química: "Quando (...) dois gases $(\ldots)$ se misturam na presença de um filamento de platina, formam o ácido sulfúrico. Esta combinação apenas se realiza se a platina estiver presente; todavia o ácido recém-formado não contém traço algum de platina e, efetivamente, a própria platina não é afetada; permaneceu inerte, neutra e não modificada. A mente do poeta é o pedaço de platina" (Eliot: 1919, 7). Para que a crítica portanto se descartasse da segunda força que gerava o poder do crítico na camada precedente, foi necessário exilar a voz do autor, distingui-la de seu produto, para então recusar seu direito especial sobre a interpretação do que fizera. Daí resultou o desprestígio do autor em tudo que diz respeito à interpretação da literatura. (Consequência que talvez tenha ido além do propósito de Eliot, mas à qual ele próprio estoicamente aguentou, nunca se manifestando sobre o que se escrevia acerca de sua obra).

O poder do crítico contemporâneo edificou-se sobre o exílio do autor. Para este, muito contribuiu, na frente anglo-saxônica, o prestígio da ensaística eliotiana, ao passo que, na frente continental, para tanto decisivamente concorreu a influência do marxismo e da psicanálise.

Antes de passarmos ao exame da legitimidade deste exílio, convém acentuar que a estética, primeira força geradora do poder de interpretação na segunda camada, não sofreu o mesmo questionamento. $\mathrm{O}$ ensaio de $\mathrm{P}$. Valéry, "Discours sur l'esthétique", de 1937, não recebeu o favor que logo cercara o "Tradition and the individual talent" de Eliot. Em virtude desta diversidade de questionamento, a terceira camada veio a se caracterizar pela conjunção de duas forças geradoras de poder: a explicação direta ou indiretamente fundada em moldes estéticos, cujo prestígio permaneceu portanto inabalável, a análise baseada no comportamento verbal do texto, da responsabilidade de um crítico.

De posse destes esclarecimentos preliminares, avançamos nosso ponto de vista: a base sobre a qual se cria o poder do crítico contemporâneo é uma base equívoca. Nossa peça acusatória não será aqui toda apresentada, pois já pressupõe a discussão sobre a razão e os limites da estética (cf. L.C.L.: 1973, cap. I e L.C.L.: 1975, 155-203). Concentramo-nos apenas na validade da substituição do autor pelo crí- 
tico, como intérprete eficaz. Mas o leitor que conheça a obra de E. Hirsch. Jr. poderá supor que reencontrará os argumentos que tornaram famoso o teórico norte-americano. Para não atrapalhá-lo como uma falsa pista, digamos de início que, embora venhamos a considerar e a aproveitar a reflexão de Hirsch, nossas posições são bem diversas.

Para Hirsch, impõe-se o retorno dos "exilados", pois sem o privilégio da voz autoral a crítica continuará a ser uma babel de contrariedades: "De fato, se o significado de um texto não é o de seu autor, nenhuma interpretação jamais poderá corresponder ao significado do texto, pois o texto não poderá ter significado algum determinado ou determinável" (Hirsch: 1967, 15). De nossa parte, afirmamos que o privilégio do crítico não passará de uma simples mudança de "proprietário", com a manutenção do mesmo "regime de propriedade", se o novo ocupante não se qualificar pela exploração mais eficaz da terra do texto. Ou seja, pelo rigor demonstrativo de sua linguagem. Isso sem dúvida já era previsto no ensaio-programa de Eliot. Mas, em vez de cairmos na analogia fácil do caso com o de revoluções políticas que terminam por mostrar sua mísera face reformista, é mais fecundo notar que, entretanto, não seria esperável, nos anos próximos, a publicação do ensaio de Eliot, que já se observasse o desacordo entre a proposição programática $\mathrm{e} o$ trabalho efetivo do crítico. Em Eliot, encontrava-se o "manifesto" que justificava a tomada do poder, enquanto nem ali nem em outro lugar se depositavam os conceitos que presidiriam à nova prática. Foi necessária a experiência dos últimos cinquenta anos para que, agora, observemos o desacordo ainda vigente, malgrado a extrema qualidade das obras de um Auerbach e de um Benjamin, entre o mandato do intérprete e seus efetivos ocupantes.
Declarado nosso ponto de vista, vejamos como conduzi-lo. Comecemos pela trilha mais fácil, desenvolvendo por que o privilégio do crítico não se fez acompanhar da mudança do "regime de propriedade". Utilizando os passos de Hirsch, notemos que uma das afirmações justificadoras do exílio do autor consiste em dizer que a interpretação da obra muda para seu próprio criador. (E quem conhecer escritores já poderá tê-lo concluído por experiência própria). Como Hirsch bem assinala a propósito, a frase se monta sobre o equívoco de tornar sinônimos dois conceitos entretanto independentes: o conceito de significado (meaning) e o de significação (significance). Sem repetirmos seu exame detalhado, diremos que por efeito de significado se entende a compreensão do que o autor quis dizer por seu texto efetivo, enquanto por efeito de significação se entende o julgamento estabelecido a partir da compreensão (ou incompreensão) do significado. Por exemplo, ao assistir uma conferência, o exato entendimento do que escutei diz de seu significado. Se, entretanto, não me limito a escutar e a entender, mas concedo uma valoração ao que ali se disse, esta valoração concerne à significação por mim emprestada ao falado. Parece óbvio que esta valoração não depende da apreensão correta do significado; ao contrário, independentemente de ser positiva ou negativa, ela pode ocorrer a partir da incompreensão - reconhecida ou não pelo ouvinte - do significado. Acrescente-se ainda que, para Hirsch, o significado não se confunde com a intenção do autor, porquanto poderá suceder que ele não tivesse consciência de certa associação, da qual entretanto nada impediria que estivesse consciente. Por exemplo, ao escrever este ensaio não me preocupo, donde não estou consciente com a área da qual esteja retirando minhas mais freqüentes metáforas. Se um leitor então me diz 
que elas são tomadas da área jurídica, não terei dificuldades em concordar com ele. Segundo Hirsch, tais metáforas pertenceriam ao significado do texto, enquanto participantes de sua escala inconsciente (como se vê, o inconsciente para Hirsch nada tem a ver com a sua conceituação psicanalítica, sendo sinônimo do que mais comumente se chamaria de o implícito). Por conseguinte, sai do campo do significado tudo aquilo de que o autor não poderia estar consciente, dada a sua situação histórica. Seria o caso da luta de classes para Balzac ou do complexo de Édipo para Sófocles ou Shakespeare. Segundo o autor norte-americano, dar acesso, no ato da interpretação, a elementos nos quais o autor não poderia ter pensado seria tornar dominante o efeito de significação, convertendo o resultado da análise em arbitrariedade.

Embora a conclusão de Hirsch nos pareça pobre e inadequada $-o$ fato de não existir o conceito de complexo edipiano não significa que ele não esteja no drama sofocliano, pois o conceito não cria a realidade -, ele tem sem dúvida o mérito de haver acentuado as distorções a que o crítico chega ao confundir meaning e significance (6). Tornando-os equivalentes, o crítico não se coloca o problema da pluralidade das interpretações ou o coloca para escamoteá-lo, justificando a dispersão interpretativa como resultante do "plural do texto" (Barthes). Em palavras mais diretas: a literatura é um discurso polissêmico, portanto não há o que estranhar serem plurais suas interpretações. A formulação parece conter um sadio liberalismo. Mas, como é costumeiro nas explicações liberais, elas antes escondem do que revelam sua motivação. Até que ponto o "plural do texto", a polissemia literária não é estimulada pela indistinção entre significado e significação? Sem nos questionarmos a respeito, criamos um verdadeiro círculo - variante do famoso "círculo hermenêutico" (7): não há o que dizer sobre as múltiplas e diversas interpretações do mesmíssimo objeto, pois este é polissêmico! Se entretanto, aceitarmos que o efeito de significação consiste em projetar sobre a decodificação de um texto primeiro a leitura de um "texto" segundo, projeção pela qual o intérprete se torna, a pretexto de falar de um outro texto, o leitor de si mesmo, teremos, ao menos em hipótese, de considerar que aquele plural é inflacionado pela insuficiência da base que o justificara. A hipótese, concebível a partir de Hirsch, nos levaria a suspeitar de um conteúdo classista na liberal teoria da literatura como discurso polissêmico. Com efeito, ao aceitá-la literalmente, não deveríamos acatar qualquer interpretação, desde que conduzida com uma certa coerência? Por que, contudo, isso não se dá? Sem dúvida, porque a composição interpretativa deve mostrar o conhecimento de certa retórica, a prática de certa estilização, que não se possui pelo mero fato de se escrever em sua língua materna. A polissemia é respeitada quanto aos praticantes de uma escrita cujo perfil estilístico indique pelo menos formação universitária, o que, numa sociedade estratificada, significa pertencer a uma determinada camada social. Aqui entraria o questionamento da explicação estética, meio de perpetuação de um poder que se legitima por anular previamente a indagação de sua objetividade.

Nossos resultados contudo não nos tranquilizam. Se significado e significação são conceitualmente distintos, daí porém não se deduz que possam ser separados por completo. A própria preocupação com sua pureza leva ao empobrecimento da tarefa interpretativa, bem como a colocações das quais discordamos. Assim, por exemplo, o postulado de Hirsch sobre as relações entre a temporalidade histórica e os dos efeitos. $\mathrm{O}$ efeito do significado seria intemporal, 
ao contrário do efeito de significação. A análise portanto nos remeteria a um núcleo imutável. Mas esta imutabilidade é feita através de um juízo de probabilidade sobre o que o autor teria implicitamente querido dizer, probabilidade que varia de acordo com a possibilidade de conhecimento da época do autor. De tal modo o imutável é assim dependente de dados mutáveis, históricos, que, quando nada, parecerá ousada a afirmação da imutabilidade. Este problema, talvez insolúvel dentro da posição de Hirsch, recebe uma resposta menos estéril se associarmos os termos significado e significação a um terceiro, o sentido. Por ora, apenas antecipando o que desenvolveremos pouco depois, diremos que o papel do sentido é testar, corrigir, outras vezes ampliar o que se apreende pelas significações despertadas no analista pela obra. Isso quer dizer que concebemos a tarefa do analista como a da distinção entre dois efeitos e um plano - o plano do sentido - a constituir. Tal plano, ausente do ponto de vista da leitura sintagmática, supõe o entendimento adequado do enunciado verbal (de seu significado), o reconhecimento das significações que ele despertou e, a partir daí, a tentativa de construção de uma rede de articulações lógicas, que dê conta, quer do significado, quer das significações que recebeu. O problema então se desloca da intenção implícita do autor para a maneira como se constrói um núcleo de cuja leitura nascerá a interpretação. Esta, não mais baseada em uma leitura horizontal ou sustentada por juízos advindos desta leitura, tampouco se pretenderá fora da história. Ela é histórica a partir mesmo dos instrumentos teóricos que a moveram.

Observe-se de passagem que a hierarquia estabelecida entre significado, sifnificação e sentido receberia outra disposição se cogitássemos da tarefa do poeta. Ao contrário do crítico, seu tra- balho consistirá não no controle e no teste das significações que outro texto nele despertou, mas sim no próprio fecundar daquelas significações, convertidas em alimento de sua própria obra. Se a leitura do poeta sobre a sua obra não nos dá o sentido da mesma, é pela mesma razão por que um sonhante não descobre o sentido de seu sonho. A comparação ainda se impõe noutro ponto: em ambos os casos, a interpretação fornecida pelo que sonha ou escreve é preciosa e fundamental para o analista.

Relacionando a sequência do parágrafo anterior com o que escrevemos atrás, diremos que, se o crítico não cuida das diferenças entre os efeitos - quer concorde ou discorde de sua suficiência, quer sinta ou não a necessidade de introduzir um terceiro termo - ele passa a ocupar ilegitimamente o lugar que hoje o distingue, pois, teoricamente, nada impugna fosse este lugar preenchido pelo autor. No fundo, entretanto, a ocupação por um ou por outro seria igualmente ilegítima, pois justificada apenas pelo prestígio do nome - antes o do autor, hoje o do crítico - e por sua capacidade de persuasão. Deste modo, através de uma demonstração que supomos simples, voltamos ao que afirmáramos como ponto de partida. Ao invés de procurarmos agora novas provas do ponto de vista que defendemos, parece-nos preferível introduzir um dado correlato: refiro-me à resistência que o crítico - e não só o meio literário dos leitores e dos autores manifesta quanto à procura de rigor. Ele como receia que a sua obstinacão rompa seu contato com a obra literária. Este temor tende hoie a ser aumentado em virtude de experiências de "rigor" que não passam de metáforas da castração. Não é expurgando as significações que chegaremos a algum resultado aproveitável, mas sim tendo meios de submetê-las à pergunta sobre sua objetividade. 
Através de tal controle o que na verdade se perde é a continuação da experiência estética. E aí está a extrema dificuldade de sua tarefa. $O$ que seria impossível a um amante - saber por que ama a quem ama — se torna necessário ao crítico. Se a sua atividade, como a concebemos, é viável, será porque o investimento libidinal na escritura analítica e na escritura do corpo não é o mesmo. Ora, à medida que não se questiona o valor da explicação estética, com razão o crítico temerá permanecer no seio de uma exigência que, de fato, o distancia do solo daquela explicação. Convém portanto notarmos o que há de correto e de falso na questão.

Nenhuma exigência de rigor deverá afetar a experiência estética. Esta é um dado a priori: aproximo-me de um texto e não de outro, escolho-o, interesso-me vitalmente por ele por efeito das ressonâncias estéticas em mim despertadas. Se, contudo, no momento de analisá-lo, continuar a agir com elementos mentais e emocionais semelhantes, não terei condições de questionar as significações que em mim se formaram e minha tentativa analítica será prejudicada pela identificação que guiara a experiência da escolha. Por certo, como afirma o representante mais conhecido da Rezeptionästhetik, H. R. Jauss, "o prazer estético é sempre uma liberação de algo, assim como a liberação por algo. A disposição de alguém de usufruir um objeto pressupõe a negação da vida cotidiana" (Jauss: 1974, 286). Mas esta liberação de algo, da vida cotidiana, não é, inevitavelmente, como insinua o autor, em favor de um alvo que beneficiaria o conhecimento da obra. Ao contrário, o mais provável é que o alvo seja uma compensação pelo que se negou, tanto mais fácil de ser negado quanto, em troca, crescerá a satisfação narcisista do crítico, co-autor do que antes não trazia o seu nome. Vemos deste modo a solidariedade mantida entre as duas forças
- a explicação estética, a importância atribuída ao crítico — que legitimam o crítico contemporâneo. A revelação deste íntimo engarce nos ajuda a melhor compreender os resultados a que chegamos: é mesmo porque a necessidade de rigor leva ao questionamento do papel da estética que o crítico, em um movimento quase automático de defesa, resiste ao rigor exigido. Pois fazê-lo será ameaçar sua própria posição. A pouca consistência da linguagem crítica se relaciona pois com a resistência em ultrapassá-la. Não seria entretanto exagero falar-se de pouca consistência da linguagem crítica? Examinemo-lo por um outro caso. Ele não deve ser nada sofisticado, mas pelo contrário bem elementar.

Que pergunta mais elementar poderá ser feita além daquela que se indague qual o objeto de certa atividade? Qual é, portanto, para os críticos, o seu objeto? Em ensaio datado de 1951, Wimsatt, sem dúvida o melhor teórico do new criticism e dos mais importantes no panorama atual, declara ser oportuno advertir para um fato de relevo: “... no discurso verbal, estão unidas e são mutuamente dependentes duas espécies de verdade, a da asserção ou correspondência (o realce da explicitude) e a da estrutura ou coerência (o realce da implicação)" (Wimsatt: 1951, 9). Logo a seguir o autor acrescenta que "a poesia é uma espécie complexa de construção verbal, em que a dimensão da coerência é, por várias técnicas de implicação, amplamente intensificada e, assim, gera uma dimensão extra de correspondência com a realidade, a dimensão simbólica ou analógica" (idem, idem). Sem possibilidade de erro, daí se deduz que a tarefa básica do crítico consiste em descobrir o plano da coerência, "the accent of implication". No final de seu ensaio, Wimsatt retorna ao argumento anterior e escrcve: "E importante observar que $(\ldots)$ o processo 
da explicação tende fortemente a ser não só a explicação do explícito, mas também a explicação do implícito ou a interpretação do estrutural e do formal, a verdade do poema sob seu aspecto de coerência" (Wimsatt: 1951, 24).

O cotejo das duas passagens demonstra que "implication" e "implicit" são considerados sinônimos. A equivalência seria trivial se suas consequências não convergissem com as identificações já assinaladas, entre significação e sentido, entre experiência e explicação estética. Assim dizemos porque uma crítica que se limitasse a revelar a coerência do implícito ou seria muito pobre, embora esclarecedora - como é o caso da "explication du texte" —, ou rica de sugestões, embora não fundada — a exemplo da grande maioria da crítica recente. Este duplo risco se reduzirá se a crítica ao invés operar sobre a implicação de um enunciado, pois então seu caminho seria um só: descobrir a totalidade das possibilidades semânticas dos componentes dos principais enunciados de um texto. Assim, onde se lesse "árvore" quase forçosamente a implicação haveria de realçar galhos, tronco, folhas e raízes. Ou, se o crítico combinasse a leitura de Wimsatt com a dos estruturalistas, quase inevitavelmente viriam oposições do tipo alto-baixo. Mesmo sem haver aprofundado o problema, Wimsatt parece haver procurado resguardar-se do perigo, tornando sinônimos termos que logicamente não o são. Se o nosso exame contudo estiver certo, a equivalência será sempre desastrosa, qualquer que seja o modo de seu emprego. Em lugar de acatá-la, parece mais útil desenvolvê-la para que uma questão tão primária quanto a do verdadeiro objeto da crítica receba melhor equacionamento. Retomemos pois seu exame, esforçando-nos primeiramente em diferençar o implícito do implicado, para depois verificarmos que dizer sobre o objeto da crítica.
O implícito é uma paralela que acompanha o explícito textual. É portanto sinônimo do significado "inconsciente" de Hirsch. Ele não permite senão a glosa. Mais próxima do efetivamente dito ou mais arbitrária em relação a ele, a leitura do implícito nunca desconstitui o dito, i.é, nunca mostra o que o motiva, a carga semântica que se esconde de seu significado e/ou que provoca as significações que se lhe emprestou. A implicação, por outro lado, abre um leque tão vasto e tão inespecífico que antes seria um serviço para os dicionaristas do que para o conhecimento de um texto em particular. Ao analista do discurso - e não só ao crítico literário - caberá sim descobrir o seu objeto entre o plano da implicitude e o da implicação. Melhor dito, em descobrir os mecanismos limitadores da implicação. Tais mecanismos são extraídos dos contextos intra e intertextual. Exemplo de limitador intratextual é fornecido pela rima, que "realmente pode fornecer uma informação ao limitar as possibilidades de interpretação, assim como o portador (vehicle) de uma metáfora nos força a limitar as interpretações possíveis do conteúdo (tenor) (nem tudo de $x$ ou o todo de $x$, mas apenas aquilo de $x$ ou partes de $x$ que se comparam ao portador $v$ por alguns aspectos importantes)" (Chatman: 1960, 153) (8). No caso da prosa, não há indicadores externos semelhantes à rima. Assim o analista há de se mostrar muito mais atento até conseguir a superposição de segmentos sintagmáticos que revelem a área e os limites da implicação. Quanto ao contexto intratextual, chamamos especialmente a atenção para os textos de Auerbach sobre Baudelaire e sobre a expressão "la cour et la ville" (ambos in Auerbach: 1951).

Dissemos há pouco que o objeto da crítica consiste em descobrir os limitadores da implicação. Cabe então acres- 
centar que esta descoberta se realiza através de uma leitura específica, porquanto não centrada na cena sintagmática. Ela, com efeito, parte do dito para encontrar o entredito (cf. L.C.L.: 1974, 17-24), realizando o que chamamos de plano do sentido. Descritivamente, pois, o plano do sentido supõe: a) uma construção, b) efetuada pela articulação de elementos implicados, c) cuja extensão é determinada por mecanismos intratextuais e/ou extratextuais. Por hipótese, podemos ainda declarar que o plano do sentido apresenta o inconsciente mobilizado por um enunciado particular (o texto-objeto). Assim caracterizado, o sentido corresponde ao que Lévi-Strauss chama o modelo da estrutura. Se não optamos simplesmente por estes termos já consagrados é porque preferimos adotar um caminho mais explicativo, que nos levasse a designações menos sobrecarregadas, que, ademais, nos permitisse dizer algo de menos impreciso sobre modelo e estrutura. Podemos assim observar agora que a estrutura não se confunde com o implícito, sendo, ao contrário, dependente dos limitadores da implicação, exigindo por conseguinte uma leitura que não se encerre em sua face temática. Mais importante que este esclarecimento é o seguinte: a estrutura é o antípoda da fixação do mesmo, i.e., do que se mostra constante em um número finito de variantes. Já, há vários anos, Gouillon escrevera: "O estruturalismo propriamente dito começa quando se admite que conjuntos diferentes podem ser aproximados não a despeito, mas em virtude de suas diferenças, que se procura ordenar" (Pouillon: 1966, 744, grifo meu). Por isso, menos que um núcleo estável, a estrutura aponta para a instabilidade do estruturado, formando-se um campo cujos componentes - textos diversos que, muitas vezes, nada parecem ter em comum - se comunicam, não por efeito de suas semelhanças, mas em decorrência da ordenação de suas diferenças, por meio das transformações que conduzem este texto àquele outro. Quanto ao problema do modelo, preferimos falar em plano do sentido por dois motivos: a) porque não conhecendo suficiente matemática, nossa proposta seria criticável pelo uso impreciso de um termo que, em matemática, tem um delineamento exato; $b$ ) porque, leigamente, modelo se associa a padrão, algo que se tem a priori e que predetermina os resultados a que se chegaria.

$\hat{E}$ justo entretanto que se pergunte em que a concepção expressa de estrutura contribui para levantar, ou pelo menos diminuir, a arguída ilegitimidade do direito de interpretação pelo crítico. Devemos de início declarar que a preocupação com a estrutura e com os conceitos paralelos de inconsciente e cena paradigmática. com seus meios operacionais - o princípio da comutação, de limitador lógico - pressupõe a idéia de que a ciência é uma forma de legitimação do conhecimento, na verdade a única forma capaz de verificar a objetividade do conhecimento. Ela não é uma forma de conhecimento privilegiada, senão do ponto de vista de sua testabilidade. É claro que, se não concordarmos com este ponto de vista, todo o esforço que fazemos será em vão. Enquanto, porém, não encontrarmos explicitada uma oposição desta ordem, deveremos nos preocupar com as objeções formuláveis a partir do solo da ciência. Imediatamente, nos vêm à mente duas contestações: 1) a análise estrutural supõe a existência de um corpus dotado de uma acentuada estabilidade. Sem ela, o seu objeto adquiriria novos formatos enquanto seu estudo se processava. Noutras palavras, para que o método demonstre a instabilidade do estruturado é preciso que o objeto apresente uma certa estabilidade temporal, que a história não tenha um ritmo tão acelerado que a sua metamorfose não impo:- 
sibilite o ritmo mais lento da reflexão estrutural. Ora, o discurso literário não vive na "sociedade fria" em que os mitos proliferam. Isso significa que a análise estrutural encontra, face a ele, obstáculos bem diversos dos que acompanharam a aplicação canônica do método (basicamente, nos quatro volumes de Mythologiques).

Por sua gravidade e, principalmente, por não termos resposta convincente, o problema não será atacado nesta introdução. Deixamo-lo como interrogação em estado puro, na esperança de que nossa travessia pela obra de Cornélio Penna nos dê elementos para uma melhor reflexão futura. Por estas razões, nos inclinamos para a segunda contestação, talvez menos problemática: 2) toda interpretação repousa sobre um fundo metafórico. Qual a sua validade, portanto, se ela não resgata as metáforas inesgotáveis? Daí se tem inferido que a fixação de um sentido seria uma parada arbitrária contra a dinâmica ou a pluralidade do texto; uma violentação contra o leitor; um recurso escamoteador, pois não se dá conta das metáforas que emprega para "explicar" as metáforas de seu objeto. Embora tais consequências não sejam expressamente formuladas por Derrida, aparecem entretanto coladas à sua reflexão. Notemos como a colocação se formula e quais seus efeitos.

A reflexão do filósolo francês, tal como exposta em "La Mythologie blanche", supõe sua discordância com a tese de Jakobson, segundo a qual a metáfora e a metonímia seriam de igual os mecanismos geradores da linguagem (Jakobson: 1956). A indagação de Derrida, ao invés, ressalta a metáfora e lhe assegura uma posição diversa: não geradora $n a$ linguagem, mas $d a$ linguagem. Com efeito, embora o objeto explícito do ensaio de Derrida seja a linguagem filosófica, seu alcance é mais vasto: a metáfora manteria esta fundamentalidade quanto a toda linguagem, sendo portanto indispensável compreender o seu lugar ímpar se quisermos pensar o problema da interpretação. Analisando o argumento por partes: ainda refletindo sobre a linguagem filosófica, Derrida a intitula de "mitologia branca" por ser uma linguagem em que se deteriorou a cena fabulosa, a arquitetura imagética, a qual, no entanto, aí permanece inscrita, como se traçada por tinta invisível. Por este tratamento, o autor aponta para uma conclusão mais geral: o conceito não é bem o que se opõe à cena fabulosa - cena em que as metáforas fermentam - , mas sim o que a contém sob disfarce, tornando-a ignorada de seu usuário. Daí que seria preciso transmitir à interpretação "este valor de usura" (Derrida: 1971, 6), entendendo-se por usura a qualidade do que se mantém através do desgaste. $\mathrm{O}$ que equivale a dizer: quer a linguagem filosófica, quer a interpretação em geral, não ultrapassam o âmbito da "abstração empírica sem abandono do solo natal" (idem, idem). Esta marca indissolúvel seria a consequência de a linguagem estabelecer-se através de uma analogia, analogia entre comparados dissemelhantes: a palavra e seu nomeado. Daí, dentro desta linha, dizer com justeza Silviano Santiago que o conceito vive de "a identificação do não-idêntico" (Santiago, S.: 1975, 15). À diferença de Jakobson, a analogia é percebida no momento mesmo da instalação da linguagem; a analogia que se processa dentro dela, pelo eixo da seleção, já é dependente de uma analogia entre ela e algo diverso dela, conferida mesmo em sua "origem": "Analogia no interior da linguagem se acha representada por uma analogia entre a linguagem e outra coisa que não ela" (Derrida: idem, idem).

Pensando com seriedade na proposição do autor, notamos constituir-se a 
partir dela o seguinte encaminhamento alternativo: ou daí extraímos que, sendo todo conhecimento não matemático fundado em uma linguagem natural, toda interpretação, que não seja uma paráfrase, representa um ato de construção, i.e., algo incerto, pois nunca haverá tamanha transparência do conceito que ele terminasse por coincidir com o seu objeto. Mesmo a suposição desta coincidência seria uma metáfora nociva, por supor a possibilidade de a interpretação significar o alcance da coisa em si, em sua determinação natural, fora das armadilhas da linguagem. $\mathrm{O}$ rumo contraposto destacará, ao invés, que toda interpretação participa de um plural, de uma mesma e necessária pluralidade, a qual, já pela posição princeps da metáfora, é inesgotável. Ou seja, a interpretação seria indecidível. Donde qualquer preocupação com a cientificidade da interpretação será ridícula. (No último Barthes, encontra-se o exemplo mais ilustre da acolhida desta tese).

Se examinamos a alternativa formulada - a interpretação como construção, a interpretação como indecidibilidade - , podemos ter a impressão de ser ela falsa, pois a idéia da interpretação como construção e não reencontro não invalida per se a idéia da pluralidade interpretativa. Mas a conciliação é falsa; aceitá-la será não perceber as diferenças mais profundas.

$\mathrm{Na}$ primeira posição, aceita-se a marca do conhecimento como ruptura, violação e, daí, possibilidade de constante criação, a qual exige algo além de seu aparato demonstrativo, i.e., sua experimentação. $\mathrm{Na}$ segunda, ao invés, encontramos uma cumplicidade - tática ou nostálgica, conforme seus praticantes - com a questão da origem. A origem é aquilo que se confessa perdido, mas nunca esquecido, sendo por conseguinte uma marca que sempre orienta a pesquisa. Quando então Derrida escre- ve: "Se quiséssemos conceber e classificar todas as possibilidades metafóricas da filosofia, pelo menos uma metáfora sempre permaneceria excluída, fora do sistema: (...) a metáfora da metáfora" (Derrida: 1971, 9-10), mostra que a "origem" da analogia, a metametáfora, é um vazio que lhe importa mesmo por ser um irremediável vazio, que justifica a maneira de proceder de seu discurso interpretativo: menos uma penetração na rede metafórica do texto-objeto do que uma participação nela, pela qual se continua a ativar a metaforicidade do texto em análise. Deste modo, comporta-se de modo contraposto ao que se dá por parte de quem aceita a interpretação como construção, pois, para este, a questão é estancar o jogo metafórico, através da descoberta de sua motivação, demonstrada pelo conjunto do sentido. A via de Derrida implica o prosseguimento das infinitas combinações metafóricas. Ao se saber mitologia branca, a filosofia se saberia da mesma natureza que a literatura, a qual ainda receberia a "crítica" como um outro gênero seu. E aqui percebemos o retorno tático à idéia de origem: porque perdida, jamais haverá um fim para a metaforicidade, que seria então a prova em negativo da origem.

$O$ texto que o filósofo francês anteriormente dedicara à farmácia de Platão bem nos mostra a direção de sua rota. Contentamo-nos com um pequeno exemplo. Ao longo de seu ensaio, Derrida se esforçara em apreender a cadeia central sobre cujo campo semântico se elaborara basicamente o Fedro. $\mathrm{O}$ exame do texto, bem como doutros diálogos platônicos, já lhe permitira estabelecer a série: pharmakeia - pharmakon pharmakeus. Derrida julga então necessário acrescentar um outro elo, que "entretanto parece ausente do "texto platônico"' (Derrida: 1968, 148). O autor usa as aspas para chamar a atenção sobre o problema capital do que é 
avsente ou presente no texto. Podemos sipor - supor porque não somos nem filósofos nem helenistas - que tenha razão em denunciar a estreiteza com que o problema tem sido tratado. Deverá ainda estar certo quando declara não haver "com todo rigor um texto platônico, encerrado em si mesmo, com seu dentro e seu fora" (idem, 149). Estas considerações encaminham para a justificativa do elo pharmakos. Não presente no texto platônico, teria, contudo, direito de entrada na análise por efeito de duas proximidades: 1) enquanto pharmakos é sinônimo de pharmakeus, empregado por Platão, tendo porém o termo ausente "a originalidade de haver sido sobredeterminado, sobrecarregado pela cultura grega doutra função" (idem, idem); 2) porque pharmakos está "presente na língua, remetendo a uma experiência presente na cultura grega e ainda do tempo de Platão" (idem, 148). Deveremos portanto concluir que o léxico genérico, contemporâneo a um certo autor, seria objeto legítimo. da pesca interpretativa, estabelecendo-se para isso um único limitador: "que as articulações sejam rigorosa e prudentemente reconhecidas" (Derrida: 1968, 149). Mas, que rigor e prudência poderão ser eficazes se são aplicadas sobre a curiosa unanimidade entre autor e o continente de sua língua? Tais postulados metodológicos só deixarão de parecer extremamente aleatórios e arbitrários se levarmos em conta a posição do autor sobre as relações entre conceito e metáfora. $\mathrm{O}$ papel de uma metodologia qualquer é estabelecer as regras de uso de técnicas e conceitos, aquelas subordinadas a estes. Mas, se a teoria que orienta o estabelecimento metodológico, parte do suposto de que não há de controlar a metaforicidade do uso dos conceitos, mesmo porque o conceito não abandona o solo da metáfora, então aquele estabelecimento é, desde logo, algo sưpeito, não importando a imprecisão em que se en- cerra. É por esta razão que a interpretação de Derrida caracteriza-se menos por uma prática de rigor — embora ele mesmo a exija - do que pela conivência com a proliferação metafórica da linguagem. A interpretação assim se torna necessariamente plural. Já não é apenas a literatura que se declara polissêmica, o mesmo passa a valer para a interpretação. Se a prática assim justificada não será bem nova, a teoria não deixa de sê-lo, donde seria exigível uma argumentação mais eficaz. Por conseguinte, em Derrida, mais do que uma correção da empresa estruturalista, encontramos uma resistência a seu projeto. Sua interpretação não pode deixar de ser tranquilizadora para os analistas do discurso. A partir de Derrida, a exigência de rigor demonstrativo passa para um segundo plano, em favor de um neo-impressionismo desbragado ou morigerado.

Se, em troca, adotamos a posição contrária, a da interpretação como construção, da construção-incerteza, diremos que compete à teoria, não a introdução de ausentes que venham aumentar as combinações metafóricas, mas sim dar condições de compreender o que falam as metáforas e, simultaneamente, de refazer o caminho que teria conduzido a tal resultado.

Tratando de problema distinto, o da relação entre o conhecimento físico e a percepção, Piaget se colocara em posição muito mais afim da que adotamos: “. . . a percepção nunca opera sozinha: não descobrimos a propriedade de um objeto senão acrescentando alguma coisa à percepção. E o que lhe acrescentamos não passa, precisamente, de um conjunto de quadros lógico-matemáticos, que são os únicos a tornarem possíveis as leituras perceptivas" (Piaget, J.: 1957, 91). E este "conjunto de quadros lógico-matemáticos" ou, acrescentamos, lógico-matematizáveis que tem o papel 
de estancar o jogo metafórico. Como entretanto todo conceito é "a identificação do não-idêntico", todo conceito estabelece uma tensão interna: procura dizer da metáfora, partindo, porém, de um campo tão simbólico quanto o da metáfora. Para então evitar - mais certo será dizer: diminuir o risco que o conceito seja parte de uma mitologia que se desconhece a si mesma, é preciso que faça parte de um sistema que não só opere, mas revele por que assim opera. Deste modo torna-se possível a outro analista descobrir a falha de uma análise precedente ou a sua possibilidade de ultrapasse. A teorização à qual um conceito se subordina pode ser mais lacunosa que a sua operacionalização, a operacionalização pode ser mais pobre do que permitiria seu perfil teórico ou ainda a teorização pode se confessar incompetente em explicar certo uso que dela se faz. Em qualquer dos casos, o campo teórico não deve ser uma mera racionalização da prática mais comum e mais fácil. O teórico há de ser tão criador quanto o objeto de criação a que se dirige, no caso o discurso, em sua espécie literária ou não. Supor o contrário será manter o mito do poeta. a incompreensão do poema e a identificação da ciência com a tecnologia.

Dentro da linhagem teórica que seguimos, a necessidade imediata de retificacão de resultados é imposta pela extrema dificuldade de semantizar-se com precisão as unidades constitutivas do plano do sentido: "As dificuldades com que se defronta o tratamento lógico-matemático (...) são doutra natureza. Têm a ver, desde logo, com o embaraço em que nos encontramos em definir sem equívoco as unidades constitutivas do mito, seja como termos, seja como relações" (Lévi-Strauss: 1971, 567). Não será, por conseguinte, alegando o "plural do texto", a polissemia da literatura que teremos oportunidade de dar algum passo adiante do ponto de vista do conhecimento. A esterilidade daí resultante não é ingênua ou inocente. À medida que por ela o poder do crítico continua a ser determinado pela posição que a sociedade lhe concede, à medida que esta concessão depende do acordo, normalmente de forma tácita, que se estabeleça entre o exercício daquele poder e os outros poderes sociais constituídos, a aludida esterilidade termina por ser socialmente justificada. Produção parasita que defende, por seu parasitismo, o status quo. Como esperamos proximamente demonstrar, em ensaio por enquanto apenas ideado, o próprio da mimesis é esconder a diferenca que sustenta quanto ao "imitado", diferenca aue impede o mimema de ser um duplo do "imitado". . . aí podemos inferir que é próprio dos discursos miméticos - os discursos da literatura, do sonho e do mito - serem virulentos e, ao mesmo tempo, esconderem sua virulência. Só analiticamente, o escamoteado se torna revelável. $\mathrm{O}$ ataque portanto contra linhas teóricas que procurem o conhecimento da metáfora - usada a palavra em seu significado amplo - , a defesa da crítica como gênero literário é feito não em favor da literatura, não em favor da gratificação do leitor, mas sim da sociedade que suscita a virulência da mimesis.

À posição que assumimos não se associa a pretensão de que a interpretação daí resultante seria a única correta, como se ela encarnasse o representante da verdade. Em ciência, proposição verdadeira é apenas aquela que, durante algum tempo, não se demonstra falsa. $O$ certo da verdade, pelo menos na ciência, é ser incerta. A pretensão de unicidade muito menos é cabível porque, ao se introduzirem novas relações, que modificarão o perfil interpretativo: "Quando se lhes define por um número restrito de oposições (...), vários mitos então se organizam em 
grupo fechado. Isso não deve fazer com que se descure o fato de que, encarados sob outras perspectivas, (os mitos) permanecem desdobrados em um hiper-espaço, onde também figuram outros mitos, cujas propriedades não são esgotadas pela análise precedente" (Lévi-Strauss: 1968, 84).

Das páginas anteriores se inferem duas consequências imediatas: a) ao crítico contemporâneo cabe, não a atitude de euforia ante o prestígio atual de que se vê cercado, mas sim a verificação da ilegitimidade com que (ainda) desempenha o direito que se lhe outorga; b) que há séculos enclausurado no âmbito das chamadas disciplinas humanistas, ele tende a gerar ou a absorver mecanismos de resistência às tentativas de melhor objetividade. Afinal qual a sua vantagem, qual seu proveito, senão o distanciamento ainda maior de nossos raros leitores?
Da consequência anterior deriva, mediatamente, uma terceira: c) o reverso daquela resistência é o fascínio que sentimos pelos padrões ditos científicos. A ciência é hoje uma espécie de ideal do ego à disposição de todos. Esta proposta contudo mascara a realidade da própria ciência, convertendo o que lhe é próprio, o trabalho incerto da construção, no que já faz parte da apropriação social da ciência: a idéia de que é uma técnica que esconjura os fantasmas, que nos oferece tranquilidade e boa posição.

Pela segunda consequência, o crítico literário deveria manter uma atitude de suspeita contra si e contra o filósofo; pela terceira, contra si enquanto facilmente levável a suspeitar do filósofo. Mas está fora de dúvida que se pode viver sem tais suspeitas e cuidados. $\mathrm{Na}$ ilegitimidade do próprio poder.

Rio, Abril e Outubro de 1975

\section{Notas}

1. Wenn die Bedingungen für die Aufnahme lyrischer Dichtungen ungünstiger geworden sind, so liegt es nahe, sich vorzustellen, dass die lyrische Poesie nur noch ausnahsweise den Kontakt mit der Erfahrung der Leser wahrt", "Über einige Motive bei Baudelaire" (1939). Edição citada: Walter Benjamin, Gesammelte Schriften, I-2, Suhrkamp Verlag, Frankfurt 1974, pág. 608. ("Se as condições para a acolhida da poesia lírica se tornam mais desfavoráveis, é-se levado a crer que a poesia lírica apenas excepcionalmente ainda mantém o contato com a experiência do leitor".

2. “... sie (die Erzählung) ist eine der ältesten Formen der Mitteilung. Sie liegt es nicht darauf an, das pure An-sich des Geschehenen zu übermitteln (wie die Information das tut); sie senkt es dem Leben des Berichtenden ein, um es als Erfahrung den Hörern mitzugebe. (...) Proust achtbändiges Werk gibt einen Begriff davon, welcher Anstalten es bedurfte, um der Gegenwart die Figur des Erzählers zu restaurieren", op. cit., pág. 611 ("A narração é uma das mais 
antigas formas de comunicação. Ela não se atém, ao contrário da informação, a transmitir o puro em si do acontecimento; o inclui na vida do que relata para transmiti-la como experiência ao ouvinte. (...) A obra em oito tomos de Proust dá uma idéia do que foi preciso para restaurar a atualidade da figura do Narrador").

3. Abra-se exceção para um Poe. Em "The Poetic principle" (publicado postumamente, em 1850), escrevia: "It has been assumed, tacitly and avowedly, directly and indirectly, that the ultimate object of all Poetry is Truth. (...) In enforcing a truth, we need severity rather than efflorescence of language. We must be simple, precise, terse. We must be cool, unimpassioned. In a word, we must be in that mood which, as nearly as possible, is the exact converse of the poetical" (cito a reedição in Selected writings of Edgar Allan Poe, Riverside Editions, Boston 1956, pág. 468-9). A exigência de Poe em favor de um modo que fosse "na medida do possível, o exato oposto do poético" se impunha não só para o poeta, no que antecipava as Fleurs du mal, como para seu analista.

4. Cf. "O Labirinto e a esfinge", introdução geral a $A$ teoria da literatura em suas fontes, seleção, introdução e organização de Luiz Costa Lima, Francisso Alves, Rio, 1975.

4. Cf. "O Labirinto e a esfinge", introdução geral a $A$ Teoria da literatura em suas fontes, seleção, introdução e organização de Luiz Costa Lima, Francisco Alves, Rio, 1975.

5. Por espelhismo conteudista entendemos que, por seu tipo de atuação, fundado na reação do leitor ante uma cadeia sintagmática, a leitura estética não tem meios contra o fato de terminar sendo predominantemente uma auto-leitura do analista, que, entretanto, pretende estar falando do outro, da obra que considera.

6. Para um aproveitamento diverso da polaridade "meaning" "significance", cf. de João Alexandre Barbosa o cap. "Exercícios de definição", in A Metáfora crítica, Perspectiva, São Paulo, 1974.

7. Para um exame agudo, embora não definitivo, da questão do círculo hermenêutico, cf. de Wallace Martin "The Hermeneutic circle and the art of interpretation", in Comparative literature, XXIV (2), University of Oregon, Eugene 1972. (Trad. brasileira in $\dot{A}$ Teoria da literatura em suas fontes, op. cit.).

8. Note-se que Chatman faz este comentário a partir de um ensaio de Wimsatt ("One relation of rhyme to reason", hoje in The Verbal icon). Isso mostra o quanto Wimsatt se aproxima da formulação que nos parece desejável, embora não a tenha explicitado. 


\section{Referências Bibliográficas}

Auerbach, E. (1951): "Baudelaires Fleurs du mal" e "La Court et la ville", in Vier Untersuchungen zur Geschichte der Französischen Bildung, Francke Verlag, Berna. Cito o primeiro ensaio por sua reedição in Auerbach, Gesammelte Aufsätze zur Romanischen Philologie, Francke Verlag, Berna 1967 e o segundo por sua tradução in $A$ Teoria da literatura em suas fontes, op. cit.

Chatman, S. (1960): "Comparing metrical styles", in Style in language, organiz. por Th. A. Sebeok, M.I.T. Press, Cambridge, Mass.

Costa Lima, L. (1973) : Estruturalismo e teoria da literatura, Vozes, Petrópolis.

Costa Lima, L. (1974): A Metamorfose do silêncio, Eldorado, Rio.

Costa Lima, L. (1975): "As Projeções do ideológico", in Cadernos da PUC, no 8, Rio.

Derrida, J. (1968): "La Pharmacie de Platon". Cito a reedição in La Dissémi...nation, Seuil, Paris 1971.

Derrida, J.: (1971) "La Mythologie blanche", in Poétique, 5.

Eliot, T. S.: (1919) "Tradition and the individual talent". Cito a reedição in Selected essays, Harcourt Brace, New York.

Hirsch. JR., E. D.: (1967) Validity in interpretation. Trad. cit. Teoria dell'interpretazione e critica leteraria Il Mulino, Bolonha 1973.

Jauss, H. R.: (1974) "Levels of identification of hero and audis New Literary History, V (2).

LÉvi-Strauss, C.: (1968) L'Origine des manières de table, Plon, Paris.

Lévi-Strauss, C.: (1971) L'Homme nu, Plon, Paris.

Piaget, J.: (1957) "Le Mythe de l'origine sensorielle des connaissances scientifiques". Cito a reedição in Psychologie et épistemologie, Gonthier, Paris 1970.

Pouillon, J.: (1966) "Présentation: un essai de définition", número especial de Temps modernes sobre estruturalismo, no 246.

SANTIAGo, S.: (1975) "Análise e interpretação", comunicação apresentada ao VII Simpósio de literatura brasileira (Brasília).

WelleK, R.: (1965) A History of modern criticism, vol. IV, Yale U. Press, New Haven.

WIMSATt JR. W. K.: (1951) "Explication as criticism", in Explication in criticism, Columbia U. Press, New York 1963. 